\title{
Support services for people who have undergone treatment for head and neck cancer: an approach to evaluating services
}

\author{
Ann Richardson ${ }^{1}$, Pauline Barnett ${ }^{1}$, Liz Horn², Kate Reid ${ }^{1}$, Wendy Mann ${ }^{3}$, Frankie Roake ${ }^{2}$, \\ Catherine Dwan ${ }^{2}$, Robert Allison ${ }^{3}$, Catriona Mackay ${ }^{1}$ \\ 1. School of Health Sciences, University of Canterbury, Christchurch, New Zealand. 2. Canterbury/West Coast Division, \\ Cancer Society of New Zealand, Christchurch, New Zealand. 3. Department of Otolaryngology, Christchurch Hospital, \\ Canterbury District Health Board, Christchurch, New Zealand.
}

Correspondence: Ann Richardson. Address: School of Health Sciences, University of Canterbury, Private Bag 4800, Christchurch 8140, New Zealand. E-mail: ann.richardson@canterbury.ac.nz

Received: February 6, 2014

DOI : $10.5430 /$ jha.v3n4p119
Accepted: May 12, 2014

URL: http://dx.doi.org/10.5430/jha.v3n4p119

\begin{abstract}
The purpose of this qualitative research was to (1) determine whether support services for people who have undergone treatment for head and neck cancer in Canterbury, New Zealand, align with current national and international guidelines and recommendations for best practice, (2) investigate the views of consumers and health service providers, about current support services and service needs, (3) develop recommendations for a coordinated support service. Interviews with consumers and with service providers, including multidisciplinary team members, were undertaken to collect information about support services for people with head and neck cancer in Canterbury. The analysis was undertaken in two stages. First, information was compared with current guidelines, and second, transcripts of interviews were analysed thematically, using a general inductive approach, to understand any issues arising for both consumers and providers. Comparison with guidelines identified many strengths and a few limitations of the current service compared with international best-practice. A number of other issues arose from the thematic analysis which suggested potential areas for improvement. Recommendations were made to support a best-practice, evidence-based coordinated support service for people with head and neck cancer in Canterbury. The method used to evaluate this service could be used in the evaluation of other intersectoral, multidisciplinary health services.
\end{abstract}

\section{Key words}

Healthcare, Evaluation, Hospital administration, Cancer, Support services

\section{I ntroduction}

Staff at Christchurch Hospital and at the Canterbury/West Coast Division (CWCD) of the Cancer Society of New Zealand noted an increasing number of people with head and neck cancer, and were concerned about whether their needs are being met.

In New Zealand over 700 people are diagnosed with head and neck cancer including thyroid cancer and secondary cancers, each year ${ }^{[1]}$. Although age-standardised incidence rates are projected to decline, the actual number of people with these cancers will continue to increase because of our ageing population and increasing population size ${ }^{[2,3]}$. 
People diagnosed with head and neck cancer may be offered one or more treatments including surgery, radiotherapy, and chemotherapy. Treatment can be disfiguring and can leave people with difficulties in swallowing and speaking, and with psychological sequelae and reduced quality of life ${ }^{[4-6]}$. Thus, people and their families need considerable support during and after treatment ${ }^{[5]}$.

Translational research in this area is timely, both in New Zealand and internationally. The UK National Institute for Clinical Excellence (NICE) recently issued guidelines for the organisation of healthcare for adults with head and neck cancers ${ }^{[7]}$. A Cochrane systematic review of psychosocial interventions for people with head and neck cancer identified limited good-quality evidence in this area ${ }^{[8]}$. In New Zealand, the Cancer Control Strategy includes improving the quality of life for those with cancer through support, rehabilitation and palliative care ${ }^{[9]}$. The Ministry of Health has issued guidance on implementing supportive care for adults with cancer in New Zealand ${ }^{[10,11]}$, and draft Standards of Service Provision for Patients with Head and Neck and Thyroid Cancer in New Zealand have been released ${ }^{[12]}$. A patient management framework guide for the care of people with head and neck cancer was also produced in Victoria, Australia ${ }^{[13]}$.

The aims of this research were:

- To determine whether the services for supporting people with head and neck cancer in Canterbury align with current national and international guidelines and recommendations for best practice.

- To investigate the views of people who have experienced head and neck cancer, and health service providers, on current support services and service needs in Canterbury.

- To develop recommendations (based on the findings from 1 and 2 above) for a coordinated support service for people who have undergone treatment for head and neck cancer in Canterbury.

\section{Methods}

A qualitative study using a general inductive approach was carried out. Interviews with people who have experienced head and neck cancer and with service providers were undertaken to collect information about existing support services in Canterbury, and to identify service needs.

People who had been treated at Christchurch Hospital (the hospital that provides treatment for patients with head and neck cancer in the Canterbury and West Coast regions of New Zealand) and/or used local Cancer Society (CWCD) Support Services were invited to take part in interviews by a researcher not involved in their clinical care. Purposive sampling was used to include those of different ages and ethnic groups, with a range of support needs following treatment of head and neck cancer.

Health service providers included representatives from primary care, the CWCD, Maori health providers, all the multidisciplinary team disciplines (head and neck surgeon, radiation oncologist, medical oncologist, plastic surgeon, oral and maxillofacial surgeon, dentist, radiologist, pathologist, nurse coordinator, nursing staff, dietitian, speech therapist, social worker, physiotherapist, occupational therapist), and palliative care staff.

Potential interviewees (health providers and people who have experienced head and neck cancer) were invited to participate. It was anticipated that 30 interviews (15 with health providers and 15 with patients) would be adequate to provide sampling to saturation. A number of factors determine the choice of sample size, including the likely characteristics of the potential population and the scope of the subject matter, but normally 12-15 interviews will prove quite adequate for a focused evaluation study ${ }^{[14]}$. Sample size and power calculations are not appropriate for qualitative research. The participants were interviewed by an experienced research assistant, using a structured interview guide (see 
Tables 1 and 2). Participants were asked to identify and comment on existing support services, and to recommend improvements to the existing services. The interviews were recorded and transcribed. The transcripts were read by three independent reviewers.

Table 1. Semi-structured interview guide for interviews with people with head and neck cancer

\begin{tabular}{l}
\hline Please could you list the support services you have received during and after your treatment for head and neck cancer? \\
Information; Speech therapy; Pain relief; Nursing; Dental care; Dietary advice; Psychological support; Social work; Other services \\
\hline What do you think about the services provided in Canterbury for people with head and neck cancer? \\
Are any services particularly good? \\
Are any services lacking? \\
\hline What do you think about coordination between the various services? \\
\hline Were you given written information which included the benefits and risks of treatment(s) at or soon after diagnosis? \\
\hline Were you offered counselling following your diagnosis? \\
If no, would you have liked to be offered counselling? \\
\hline Is there a Support and Education group for people with head and neck cancer in Canterbury? \\
\hline (For people whose treatment affected their teeth and/or jaw) Have you received ongoing dental care from a specialist dentist or oral \\
and maxillofacial surgeon? \\
\hline (For people who live outside Canterbury) What services are available to support people with head and neck cancer who live outside \\
Canterbury? \\
\hline Do you have any suggestions for ways to improve the experience of people with head and neck cancer? \\
\hline
\end{tabular}

Table 2. Semi-structured interview guide for interviews with health providers

\begin{tabular}{|l|}
\hline Please could you list the support services you know are available for people during and after their treatment for head and neck cancer? \\
Information; Speech therapy; Pain relief; Nursing; Dental care; Dietary advice; Psychological support; Social work; Other services \\
\hline What do you think about the services provided in Canterbury for people with head and neck cancer? \\
Are any services particularly good? \\
Are any services lacking? \\
\hline What do you think about coordination between the various services? \\
\hline Is there a local support team for people with head and neck cancer? \\
\hline Are all patients provided with written information which includes the benefits and risks of treatment(s) at or soon after diagnosis? \\
\hline Is counselling routinely offered to all people with head and neck cancer? \\
\hline Is there a Support and Education group for people with head and neck cancer in Canterbury? \\
\hline Do patients who require it receive ongoing dental care from a specialist dentist or oral and maxillofacial surgeon? \\
\hline What services are available to support people with head and neck cancer who live outside Canterbury? \\
\hline Do you have any suggestions for ways to improve the experience of people with head and neck cancer? \\
\hline
\end{tabular}

The initial review of the transcripts was to determine whether the support services available to people with head and neck cancer meet current guidelines. The second phase used a general inductive approach ${ }^{[15]}$ to identify themes ${ }^{[16,17]}$, an accepted method for analysing qualitative data where the analysis is guided by specific evaluation objectives ${ }^{[15]}$. Suggestions for improvements to current services were documented and recommendations for a coordinated support service for people with head and neck cancers in Canterbury were developed.

Approval for this study was granted by the University of Canterbury Human Ethics Committee.

\section{Results}

Potential interviewees (23 health providers and 16 people who have experienced head and neck cancer) were invited to participate. Interviews were completed with 21 health providers and 13 people who have experienced head and neck cancer. 


\subsection{Mapping against current guidelines}

The services available to people with head and neck cancer in Canterbury (and in regions served by the CDHB) were compared with the key recommendations from national and international guidelines below ${ }^{\text {[7, 10-13] }}$.

\subsubsection{Cancer centres}

It is recommended that services be concentrated in Cancer Centres serving populations of over a million people, to ensure that health professionals perform enough procedures to maintain their expertise ${ }^{[7]}$. The population of the South Island of New Zealand is about 1.04 million, and services are concentrated at Christchurch and Dunedin Hospitals. The benefits of centralising services to maintain the expertise of health professionals must be balanced against minimising travel and disruption for people receiving treatment. Having more than one cancer centre in a geographical area the size of the South Island can help to maintain services after natural disasters. Similar concerns were identified in the Victorian guidelines ${ }^{[13]}$.

\subsubsection{Multidisciplinary teams should be responsible for every patient}

There is a multidisciplinary team (MDT) at Christchurch Hospital. This team meets regularly, and includes members from all the disciplines recommended for a core MDT, but does not include a psychologist or psychiatrist. International guidelines recommend these disciplines be available ${ }^{[7,13]}$, and the draft Standards of Service Provision for Patients with Head and Neck and Thyroid Cancer in New Zealand also recommend that the MDT includes access to a psychologist ${ }^{[12]}$. This was supported by some interviewees. Guidelines emphasise the importance of access to an MDT, but it is not clear that everyone can access the Christchurch MDT. People who are diagnosed and treated in the private sector may not meet with the MDT. These people may be unaware of hospital-based and community-based support services linked to Christchurch Hospital, and thus may not have equivalent access to post-treatment or community-based support services.

\subsubsection{Clear systems and referral pathways should be in place for patients to be seen quickly by specialists}

In general there is good coordination between health professionals, facilitated by the ENT clinical nurse specialist at Christchurch Hospital. Coordination between some Christchurch Hospital departments, and between the public and private sector, may not be as good. People can "slip through gaps" if they change services (for instance from surgical to radiotherapy treatment) or if they transfer from private to public care. The NICE guidelines recommend that the MDT (under the overall responsibility of a lead clinician) be responsible for this coordination ${ }^{[7]}$. The draft Standards of Service Provision for Patients with Head and Neck and Thyroid Cancer in New Zealand recommend a "care coordinator" position be established to support patients through treatment and rehabilitation ${ }^{[12]}$.

\subsubsection{Support services should be available to all patients who need them}

Support services are available to all people treated in the public sector. These services are provided primarily by the CWCD. People treated only in the private sector are not always referred to the CWCD support services, and may be unaware of them.

\subsubsection{Local support teams should provide long-term support in the community}

There is no local support team for people with head and neck cancers in Canterbury. Support once people have been discharged from hospital relies on the strong relationship between the CDHB and the CWCD. The NICE guidelines ${ }^{[7]}$ recommend a local support team comprising: Clinical nurse specialist; Speech and language therapist; Dietitian; Senior nurse (management of stomas, nasogastric tubes, tracheo-oesophageal valves); Dental hygienist; Psych-oncology, liaison psychiatry, clinical psychology and/or counselling services; Local patients who are willing to provide "buddy" support and help with group rehabilitation sessions; Physiotherapist; Occupational therapist; Social worker.

The New Zealand Ministry of Health guidelines emphasise that social support is provided by many individuals and organisations; so coordination of services is important ${ }^{[10]}$. 


\subsubsection{I nformation should be collected and more research should be done}

This project was an attempt to gather information about the current services, compare them with published recommendations for support services for people with head and neck cancers, identify strengths and any gaps, and suggest improvements to current services.

\subsection{Reported themes from interviews}

Seven themes were identified from interviews with patients and providers. Quotes from respondents are identified as being from individual patients (P) or health providers (HP).

\subsubsection{Positive perceptions of current services}

All patients spoke very positively about their specialist treatment and were appreciative of the attentiveness of clinical staff. Typical comments included:

P2: "I'd have to say the hospital was fantastic. The three specialists, the oncology team were great. The nursing staff. Everybody. The radiology girls because I had it for seven weeks, you know. Fantastic.”

P5: “I’m very, very thankful and...my service was unbelievable and how lucky I was to have that service.”

\subsubsection{The need for increased psychological support}

When asked if they were offered counselling most patients said "no". Not all patients reported that they wanted counselling or psychological support, but others wished that this had been more readily available.

P10: “I didn’t really know where to go or who to ask...It's hard, you're not always going to die from cancer, thank goodness, but it's to ...tell somebody to calm down and think about the long-term thing when they may only have a short time. That was something I found particularly difficult. Something that counsellors think about... It never came up because I never thought about it until after the fact.”

Health provider respondents acknowledged that counselling was not routinely offered to patients and that the team relied on social workers for this service. It was noted that counselling at the time of diagnosis was a particular need. There were suggestions to address the deficit in psychological support. One view was that there needed to be more specialist resources either in the team or available to it. Another suggestion was that the counselling skills of the entire team should be enhanced so that all members could undertake this role.

\subsubsection{Access to support services}

Despite the presence of the CWCD in the Oncology Department, not all patients were offered support services, including being linked to Cancer Connect volunteers (people who are two years or more from their diagnosis and provide support to newly diagnosed people). Some patients commented specifically on the importance of being able to speak to someone who had experienced cancer, for example:

P8: "Two days after the operation the nurses organised a guy to come and talk to me who had had the same operation. And when I heard him talk, I thought 'it gives you confidence'.”

Access to support in the community was also mentioned, including the value of contact between appointments. Access to support services seemed to be less readily available to those who are treated privately.

P10: “...because I went privately, I felt I missed out on a little of that public side of it, like it feels they've got a sort of larger interface with the people.” 


\subsubsection{Multidisciplinary team meeting}

The MDT was recognised as important for decision-making. A number of both health providers and patients, however, felt that the experience of the meeting could be "overwhelming" for patients. Patients commented:

P2: "And the psychological support is drastic, I think they need to have a counsellor with you...everything happened within a week, from seeing the GP to walking into a room with two little red chairs and over a dozen people in it...and then blasted with 'this is what's happening', given the option there and then to proceed to have all the treatment in Dunedin...”

P6: “...it was all so quick with me,...I went in for what I thought was tonsillitis and then they told me I had cancer and about two days later I went to a meeting at the hospital...well there were twenty-five people in the room. And it was just holy hell."

Providers acknowledged that the team meeting, while effective and efficient for the clinical team, is daunting for patients and that alternative approaches need to be tried.

HP8: “I don't know whether this is the best way to deliver someone's diagnosis and their treatment plan...I think it is overpowering and disempowering and I personally feel that it should be done somewhere more privately.”

It was noted that this approach is under review:

HP 21: "We are mindful that the multidisciplinary team at the first diagnosis clinic meeting is quite intimidating and we're currently reviewing it to see if we can do it a little better.”

\subsubsection{I nformation}

People who have undergone treatment for head and neck cancer appreciated written information, but some commented that it is hard to assimilate it all. It was suggested that there should be some way of checking that people understand the information and have more opportunities to ask questions. One patient recognised the importance of two-way communication:

P4: “The specialists involved are very busy people, but I think it's important that before, during and after the treatment there is an attempt made by them to clarify the patient's understanding... And I think that making it more pro-active onto the patient and say 'look I need some information back from you to give me confidence that you really understand what's going on'.”

Another reported on a simple "information gap":

P1: "You hear of people going back every three months, I'm going back every month, does that mean I'm not performing? I don't know...So I said straight out, when will I ever extend to three-monthly visits? And they said in another two months, once you've been away twelve months from your treatment, then you can go to three-monthly. If I had known that my mind would have been at rest possibly six months ago.”

Providers identified similar issues.

\subsubsection{Service communication and co-ordination}

Positive comments were made by both providers and patients regarding the coordination between CDHB services and CWCD services. Some suggestions were made for improvements in coordination between primary care and the hospital, between hospital departments, and between regional providers. More emphasis needs to be placed on information sharing so that the patient is not repeating information.

HP 2: “...communication could be better in terms of more information, as a written referral... Providing a one-liner is not adequate when you are referring to non-Canterbury agencies.” 
HP 14: "I certainly think it needs some work....it can be a bit disjointed for patients. Lack of information sharing means they have to retell their story a lot...they find it quite wearisome.”

\subsubsection{Financial support for patients}

Some post-treatment care is not free (some equipment, dental services) and is a particular burden for some patients.

P 8: "The reason I had to pay for it, very small piece of plastic it cost me $\$ 500.00$. Now fortunately I could afford it then, I can’t afford it now. I can’t afford the equipment that goes with it. I've got to save up before I can get it.”

\section{Discussion}

This project provided information on current support services for people who have undergone treatment for head and neck cancer in Canterbury, New Zealand. Mapping against published national and international guidelines showed that Canterbury services meet most of the recommended guidelines. Information from interviews with patients and service providers identified some key themes, which complemented the mapping exercise. The service provided in Canterbury is highly regarded by the people interviewed for this project, but some suggestions for improving the service were made.

Since this research was undertaken, the policy of specialists who work in public and private sectors is that all patients are seen in the public hospital system so that they can have full access to the services available, such as social work support and speech therapy. Once patients have been assessed, they may choose to have their surgery or radiotherapy through the private system. They are then given the option of continuing with follow up in the public system or privately.

Support services for people with head and neck cancers in Canterbury rely on the strong relationship between primary care, the CDHB and the CWCD. The CWCD relies on charitable donations to support its work, and does not receive government funding, despite providing an essential service for people with head and neck cancer. One difficulty is that the CWCD may not wish to contract directly with government agencies to provide a service in case this restricts the service(s) they can offer.

\section{Conclusion}

This project has identified many strengths and a few limitations of the current services compared to international best-practice and local people's needs, and we hope it will support the development of a best-practice, evidence-based coordinated support service for people with head and neck cancer in Canterbury. Based on our findings from the mapping exercise and the interviews, we recommend the following:

- Addition of a psychologist and/or psychiatrist to the multidisciplinary team;

- Routine offer of counselling to people who have received a diagnosis of head and neck cancer;

- Individual support for people with head and neck cancer before, during, and after their meeting with the multidisciplinary team;

- Establishment of a community support team for people with head and neck cancer;

- Enhancement of communication between primary care services and Christchurch hospital-based services, between hospital departments, between private sector and public sector providers, and between hospital services and regional health service providers;

- Development of a formal agreement (such as a memorandum of understanding) to protect the current provision and coordination of services between the CDHB and the CWCD; 
- Investigation of inconsistent funding for equipment and services related to treatment of head and neck cancer, and possibilities for providing financial support for people with head and neck cancer.

This project included mapping a current service against published recommendations in national and international guidelines, and obtaining the views of service users and providers. Purposive sampling, which included representatives of the disciplines of the service providers and covered the range of support needs of service users, was appropriate for identifying the characteristics of the current service, and for a detailed qualitative analysis ${ }^{[15]}$. This approach would be useful for the evaluation of other intersectoral, multidisciplinary health services in New Zealand and in other countries.

\section{Acknowledgements}

We are grateful to the participants who generously gave their time to take part in the interviews, and provided valuable information for this project, and Jill Winter for transcribing. The Wayne Francis Charitable Trust provided support for this research.

\section{Conflict of interests}

The authors of this paper declare that they have no conflict of interests.

\section{References}

[1] Ministry of Health. Cancer: new registrations and deaths 2010. Wellington: Ministry of Health, 2013. Accompanying tables [cited 2014 January 28]. Available from: http://www.health.govt.nz/publication/cancer-new-registrations-and-deaths-2010

[2] Blakely T, Shaw C, Atkinson J, Tobias M, Bastiampillai N, Sloane K, et al. Cancer Trends: trends in incidence by ethnic and socioeconomic group, New Zealand 1981-2004. Wellington: University of Otago and Ministry of Health. 2010.

[3] Ministry of Health. Cancer Projections: incidence 2004-08 to 2014-18. Wellington: Ministry of Health. 2010.

[4] Mehanna HM, Morton RP. Deterioration in quality of life of late (10 year) survivors of head and neck cancer. Clinical Otolaryngology. 2006; 31: 204-11. PMid: 16759240. http://dx.doi.org/10.1111/j.1749-4486.2006.01188.x

[5] Mehanna H, West CML, Nutting C, Paleri V. Head and neck cancer - part 2: treatment and prognostic factors. Clinical otolaryngology. 2011; 36: 154-8. http://dx.doi.org/10.1111/j.1749-4486.2010.02232.x

[6] Luckett T, Britton B, Clover K, Rankin NM. Evidence for interventions to improve psychological outcomes in people with head and neck cancer: a systematic review of the literature. Support Care Cancer. 2011; 19: 871-81. PMid: 21369722. http://dx.doi.org/10.1007/s00520-011-1119-7

[7] National Institute for Clinical Excellence. Improving outcomes in head and neck cancers - the manual. London: NICE. 2004.

[8] Semple C, Parahoo K, Mills M, et al. Psychosocial interventions for patients with head and neck cancer: intervention protocol. The Cochrane Library. 2011. http://dx.doi.org/10.1002/14651858.CD009441

[9] Minister of Health. The New Zealand Cancer Control Strategy. Wellington: Ministry of Health and the New Zealand Cancer Control Trust. 2003.

[10] Ministry of Health. Guidance for improving supportive care for adults with cancer in New Zealand. Wellington: Ministry of Health. 2010.

[11] Health Outcomes International Pty Ltd. An Implementation Plan for the Guidance for Improving Supportive Care for Adults with Cancer in New Zealand. Auckland: Health Outcomes International Pty Ltd. 2011.

[12] Ministry of Health. Standards of Service Provision for Patients with Head and Neck Cancer in New Zealand - Provisional [Cited 2014 January 28]. Wellington: Ministry of Health. Available from: http://www.health.govt.nz/our-work/diseases-and-conditions/cancer-programme/faster-cancer-treatment-programme/tumour-standards

[13] Victorian Government Department of Human Services. Head and neck tumour stream: larynx, pharynx and oral cancer: a guide to consistent cancer care. Melbourne: Department of Human Services. 2006.

[14] Guest G, Bunce A, Johnson L. How many interviews are enough? An experiment with data saturation and variability. Field methods. 2006; 18 (1): 59-82. http://dx.doi.org/10.1177/1525822X05279903

[15] Thomas DR. A general inductive approach for analyzing qualitative evaluation data. Am J Evaluation. 2006; 27: $237-246$. http://dx.doi.org/10.1177/1098214005283748

[16] Bradley EH, Curry LA, Devers KJ. Qualitative data analysis for health services research: developing taxonomy, themes, and theory. Health Services Research. 2007; 42: 1758-1772. PMid: 17286625. http://dx.doi.org/10.1111/j.1475-6773.2006.00684.x

[17] Ryan GW, Bernard HR. Techniques to identify themes. Field Methods. 2003; 15: 85-109. http://dx.doi.org/10.1177/1525822X02239569 